\title{
O trabalho da polícia investigativa face aos homicídios de jovens em Belo Horizonte
}

\author{
Investigative police work in relation to youth homicides \\ in Belo Horizonte
}

Luís Felipe Zilli ${ }^{1}$

Joana Domingues Vargas ${ }^{2}$

${ }^{1}$ Centro de Estudos de Criminalidade e Segurança Pública (CRISP/UFMG)

Av. Antonio Carlos 6627 Campus Universitário Pampulha (Unidade Administrativa 3), Pampulha. 31270-901 Belo Horizonte MG.

zilli.felipe@gmail.com

${ }^{2}$ Núcleo de Estudos de

Políticas Públicas em

Direitos Humanos,

Universidade Federal do

Rio de Janeiro.
Abstract Over the course of the past 30 years, Brazil has experienced an exponential increase in its homicide rates, which is a problem that has been aggravated by the slaughter of young nonwhite, poor, males living in the shantytowns and communities. Given the complexity and the resurgence of the homicide phenomenon in Brazil, this article seeks to discuss some of the main effects that these trends have had on investigative police work. For this purpose, a long process of ethnographic research in six Specialized Homicide Police Units of Belo Horizonte $(\mathrm{BH})$ was conducted between the years 2009 and 2010. During this period, researchers accompanied the daily routine of these units and conducted several in-depth interviews with investigators and civil police chiefs. Among the results, the mismatch between the increasing complexity of the homicide phenomenon and the legal procedures established for investigating the problem in $\mathrm{BH}$ should be stressed.

Key words Criminal investigation, Homicides, Police investigation, Police work
Resumo Ao longo dos últimos 30 anos, o Brasil vem experimentando um aumento exponencial de suas taxas de homicídio, problema este impulsionado pelo morticínio de jovens do sexo masculino, não brancos, pobres, moradores de vilas e favelas. Diante do recrudescimento e da complexificação do fenômeno dos homicídios no Brasil, o presente artigo tem como objetivo discutir alguns dos principais efeitos que estas tendências projetam sobre o trabalho policial investigativo. Para tanto, realizou-se, entre os anos de 2009 e 2010, um longo trabalho de pesquisa etnográfica em seis Delegacias Especializadas de Homicídios da cidade de Belo Horizonte. Durante este período, pesquisadores vivenciaram a rotina diária destas unidades e realizaram diversas de entrevistas em profundidade com investigadores e delegados da Polícia Civil. Dentre os resultados destacase o descompasso entre a crescente complexidade do fenômeno criminal e as práticas e os procedimentos legais previstos para a investigação dos homicídios em $B H$.

Palavras-chave Investigação criminal, Inquérito policial, Homicídios, Trabalho policial 


\section{Introdução}

Segundo registros de Ministério da Saúde (MS), mais de um milhão de pessoas foram assassinadas no Brasil entre 1979 e 2009. Significa dizer que, em média, uma pessoa foi morta no país a cada 15 minutos, durante os últimos 30 anos, fazendo o Brasil saltar de uma taxa de 9,5 homicídios para cada grupo de 100 mil habitantes em 1979, para uma taxa de 27,1 em 2009 (crescimento de $185 \%$ durante o período). Atualmente, os assassinatos já são a principal causa de morte entre jovens de 15 a 24 anos, superando qualquer doença ou causa externa e se consolidando como um gravíssimo problema de saúde pública do Brasil.

Desagregando-se os registros do Ministério da Saúde, nota-se que a trajetória de crescimento das mortes violentas no Brasil deu-se a reboque de ocorrências que envolveram um perfil bastante específico da população: moradores de grandes centros urbanos, do sexo masculino, negros ou pardos, com idades variando entre 15 e 24 anos, baixa escolaridade e renda, feridos por arma de fogo e mortos em via pública.

Os dados também indicam que, ao longo das últimas duas décadas, os homicídios passaram a ser consumados com maior nível de violência. Até o início dos anos 1980, a maioria das vítimas era agredida por arma de fogo em via pública, mas só vinha a falecer em unidades hospitalares. Já a partir dos anos 1990, a maioria das vítimas passou a morrer em via pública, sem chance de socorro, possivelmente devido à maior gravidade ou quantidade de ferimentos sofridos. Se for levado em consideração que, nos últimos anos, houve um aumento significativo da capacidade de pronto-socorro e de atendimento nas unidades hospitalares brasileiras, este dado sugere que os homicídios passaram a ser consumados com armas de fogo mais letais e, definitivamente, com maior número de disparos.

Um levantamento a partir de laudos de necropsia emitidos pelo Instituto Médico Legal (IML) de São Paulo durante o ano de 2001, por exemplo, demonstrou que, em $69 \%$ dos homicídios por arma de fogo, a vítima foi atingida na cabeça por mais de dois projéteis ${ }^{1}$. Ao que tudo indica, boa parte dos homicídios registrados no Brasil tem assumido características de execução em via pública.

Além de atingir um segmento específico dentro do conjunto da população, os homicídios no Brasil também demonstram ter um padrão de distribuição espacial bastante concentrado: mes- mo dentro das grandes cidades, os assassinatos concentram-se em áreas de alta vulnerabilidade social e pouca ou nenhuma provisão de serviços públicos ${ }^{2-4}$. Em Belo Horizonte, por exemplo, entre os anos 2000 e 2005, cerca de $20 \%$ de todos os assassinatos concentraram-se em apenas $6 \%$ do território da cidade. E este padrão se repete em outras regiões metropolitanas do país, como São Paulo e Rio de Janeiro ${ }^{5,6}$.

Por fim, diversos estudos sugerem que o processo de recrudescimento das taxas de homicídio no Brasil se fez acompanhar por mudanças nas próprias dinâmicas sociais e criminais relacionadas à ocorrência deste tipo de crime. Até o final dos anos 1970 grande parte dos assassinatos parecia decorrer de conflitos interpessoais e localizados, envolvendo tão somente autor e vítima e motivados por questões interpessoais. A partir dos anos 1990, no entanto, percebe-se uma crescente complexificação das dinâmicas produtoras de violência letal no país, fazendo com que, gradativamente, boa parte dos crimes deixasse de se circunscrever às esferas dos conflitos interpessoais e passasse a envolver, de modo cada vez mais frequente, grupos de jovens armados e suas atividades criminosas ${ }^{7,8}$.

Os altos níveis de violência associados à atuação de gangues de traficantes em favelas das grandes cidades brasileiras agregou maior complexidade ao fenômeno dos homicídios, já que as mortes tornaram-se decorrência não apenas de conflitos de âmbito comunitário, mas também de intrincados processos de estruturação de atividades criminosas, bastante difíceis de serem plenamente compreendidos e apurados ${ }^{7,8}$. Talvez isto explique as baixas taxas brasileiras de esclarecimento de homicídios dolosos, cuja medida é obtida pela razão entre o volume de ações penais e o volume de ocorrências. No Rio de Janeiro, a taxa de esclarecimento, que já não era muito alta no passado, girando em torno dos $30 \%$, caiu pela metade nos últimos anos ${ }^{9,10}$. Segundo pesquisa recente realizada por Misse e $\operatorname{Vargas}^{10}$, de todos os homicídios consumados e tentados ocorridos no estado do Rio de Janeiro em 2005, apenas $15 \%$ foram transformados em ação penal até quatro anos após o fato. Já em Belo Horizonte, levantamento realizado por Sapori ${ }^{11}$ indicava que esse percentual médio também foi de apenas $15 \%$ entre 2000 e 2005 . No Recife, apenas $27 \%$ dos inquéritos de homicídios dolosos e latrocínios instaurados em 2007 foram encaminhados como denúncias, mas só $8 \%$ deste total produziu condenações, até dois anos depois ${ }^{12}$. 
Todas estas questões projetam importantes impactos não apenas sobre políticas de Segurança Pública, mas também sobre a rotina diária dos operadores do Sistema de Justiça Criminal encarregados do processamento destes crimes. $\mathrm{O}$ aumento das mortes violentas e sua correlação cada vez mais estreita com a atuação de grupos de jovens armados e seus intrincados processos de estruturação de atividades criminosas impõem novos desafios para os trabalhos de investigação, não raramente prejudicando todo o processo de penalização destes crimes por parte do Estado. Por outro lado, a crescente exigência pública por maior profissionalização, celeridade e eficácia dos serviços de justiça entra em conflito com a tradição inquisitorial, formalista e cartorial de um sistema processual/legal que ainda prevê instrumentos pouco flexíveis e, muitas vezes, inadequados ao processamento de fenômenos criminais cada vez mais complexos ${ }^{13,14}$.

No centro deste debate, qualquer problematização que se faça a respeito da (in)capacidade do Sistema de Justiça Criminal para prevenir, apurar, processar e penalizar ocorrências e envolvidos passa quase que necessariamente por compreender como se desenvolvem, neste contexto tão complexo, as rotinas, os procedimentos e as percepções dos policiais envolvidos com este processo. E esta é a discussão proposta neste texto.

\section{Metodologia}

Para desenvolver esta temática, o artigo baseouse em extensa pesquisa etnográfica realizada entre os anos de 2009 e 2010, em seis (06) Delegacias Especializadas de Homicídios de Belo Horizonte (MG). Durante este período, pesquisadores vivenciaram a rotina destas unidades, acompanhando investigações feitas em locais de crime, diligências, depoimentos, reconhecimentos e tantos outros procedimentos investigativos (cabe observar que a vivência do cotidiano das delegacias deu-se com absoluta liberdade de acesso, sem qualquer tipo interferência sobre os trabalhos de pesquisa).

Também foram realizadas diversas entrevistas em profundidade com delegados e investigadores da Polícia Civil, não apenas com o objetivo de compreender os instrumentos e os métodos de investigação propriamente ditos, mas principalmente de captar a percepção destes atores sobre o trabalho investigativo e os mecanismos legais prescritos para sua realização. Ao todo, foram entrevistados oito delegados e 24 investigadores.
Por fim, os pesquisadores também analisaram 55 inquéritos policiais instaurados entre os anos de 1997 e 2009 (selecionados de maneira aleatória), com o objetivo de compreender, de maneira mais aprofundada, como o processo de investigação é conduzido pela Polícia Civil e como este trabalho se relaciona com o processamento dos crimes de homicídio. Com base na análise dos inquéritos, tornou-se possível construir um quadro de quais procedimentos são mais utilizados para instrumentalizar uma investigação de homicídios, quais tipos de informações são priorizadas para a formação do conjunto probatório e, principalmente, quais impactos o caráter cartorial dos inquéritos projeta sobre a investigação dos crimes propriamente dita.

De modo geral, os procedimentos de coleta e análise de informações foram desenvolvidos de modo a contemplar cinco (05) eixos temáticos: (1) contexto político/organizacional da Polícia Civil de Minas Gerais, mais especificamente da Divisão de Crimes contra a Vida (DCcV); (2) a prática de investigação de homicídios; (3) o inquérito policial enquanto instrumento de investigação de homicídios; (4) o modelo de gestão por resultados e seus impactos na prática investigativa; (5) a percepção dos policiais sobre seu trabalho. A partir destes eixos de análise, produziram-se os resultados que passamos a expor.

\section{Os homicídios na RMBH}

Até meados dos anos 1990, a região metropolitana de Belo Horizonte ( $\mathrm{RMBH})$ mantinha uma taxa de homicídios relativamente baixa se comparada a outras capitais brasileiras. Entre 1994 e 2004, no entanto, houve um crescimento de $406 \%$, que passaram de 11,2 assassinatos para cada grupo de 100 mil habitantes para 56,7. Assim como se observou no restante do país, este aumento deu-se principalmente com a morte de jovens entre 15 e 24 anos, do sexo masculino, pretos ou pardos, assassinados por armas de fogo, nas ruas de favelas e bairros de periferia das cidades que formam o polo metropolitano. Os Gráficos 1-4 e a Figura 1 a seguir ilustram esse padrão, para os homicídios registrados na região metropolitana de Belo Horizonte, entre os anos de 1979 e 2008. Na figura, os pontos em destaque são favelas com grande histórico de violência na RMBH.

O que os dados indicam, portanto, é o aumento dos assassinatos na $\mathrm{RMBH}$ ao longo dos últimos anos decorrente do crescimento vertiginoso de um tipo bastante específico de homicí- 
dio, provavelmente relacionado à atuação de grupos de jovens armados e seus conflitos territorializados derivados de processos de estruturação de atividades criminosas.

Levantamentos realizados pela Polícia Civil de Minas Gerais em 16 favelas da RMBH entre os anos de 2007 e 2009 apontaram a existência de 55 gangues nestas localidades, com um total de 619 integrantes criminalmente ativos ${ }^{15}$. Esses dados indicam que o fenômeno das gangues na RMBH manifesta-se de maneira extremamente fragmentada, com vários pequenos grupos ocupando simultaneamente frações das favelas (o que aumenta significativamente o potencial de enfrentamento entre eles e reforça o uso de meios violentos e privados de resolução de conflitos).

Para que se tenha uma ideia do impacto que estas gangues exercem sobre a violência das favelas da RMBH, basta observar seu alto grau de participação em homicídios. Um levantamento em bases de inquéritos da $\mathrm{DCcV}$, por exemplo, indicou que, das 63 mortes registradas entre os anos de 2005 e 2008 em uma favela da região norte de $\mathrm{BH}$, nada menos do que 37 tiveram participação direta e já comprovada das gangues locais.

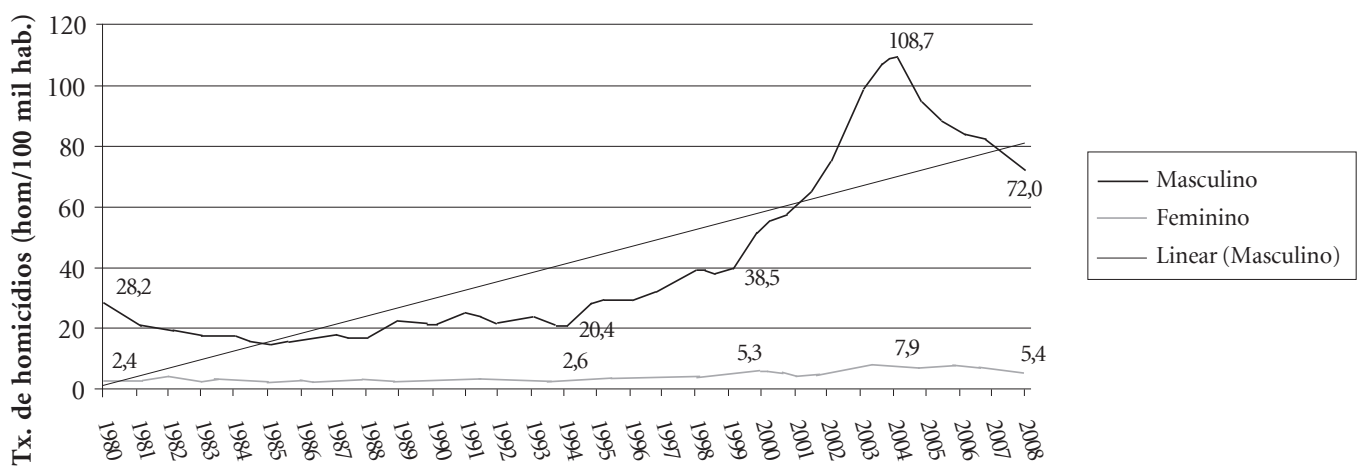

Gráfico 1. Taxa de Homicídios na RMBH (Hom/100 mil hab.), por Sexo das Vítimas - 1979/2008.

Fonte: SIM/DATASUS (Elaboração Própria)

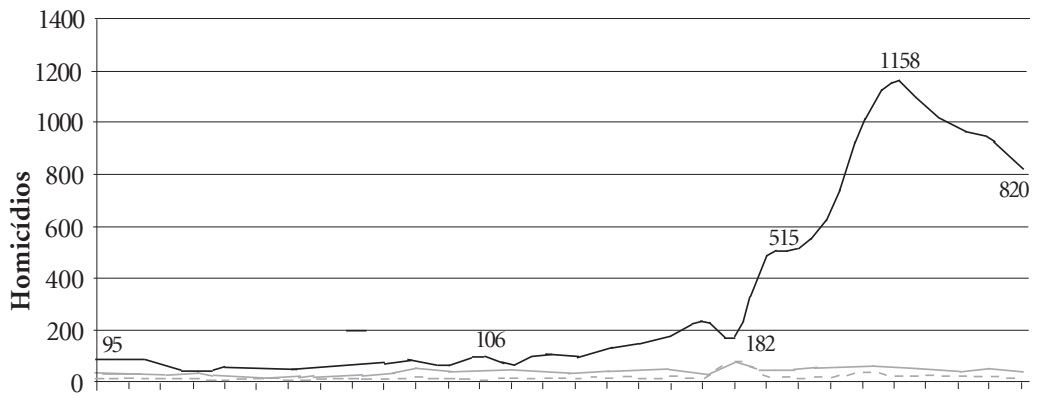

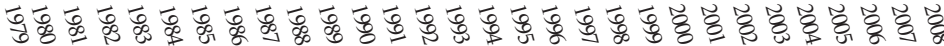

Gráfico 2. Homicídios registrados na RMBH, por meio utilizado - 1979/2008. 


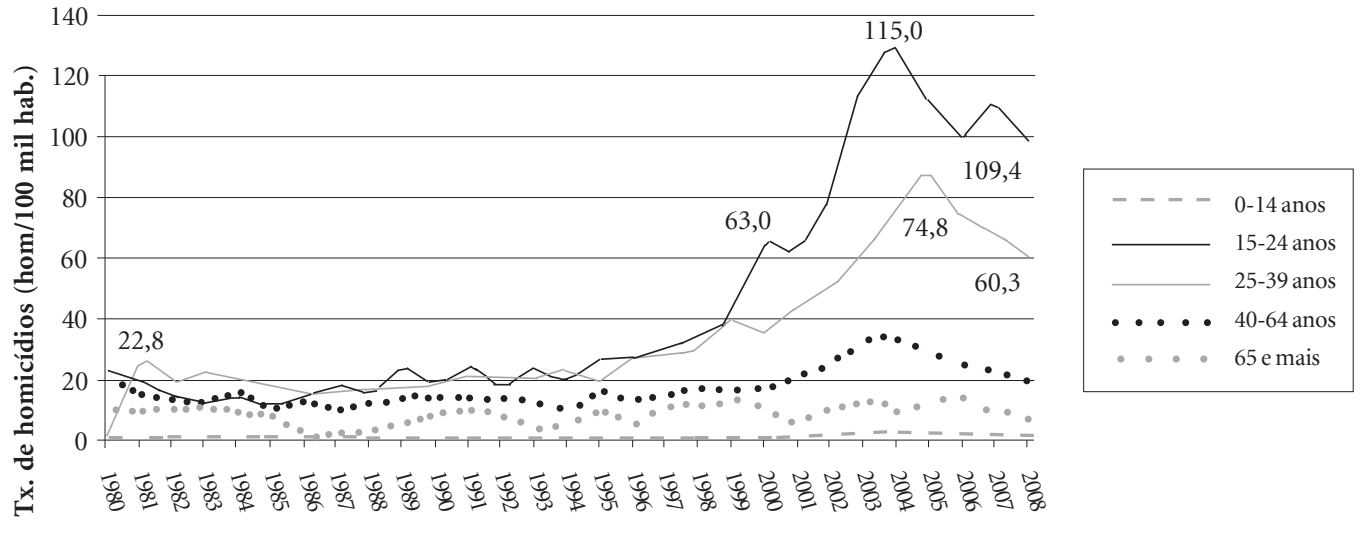

Gráfico 3. Taxa de Homicídios na RMBH (Hom/100 mil hab.), por Faixa Etária das Vítimas - 1979/2008.

Fonte: SIM/DATASUS (Elaboração Própria)

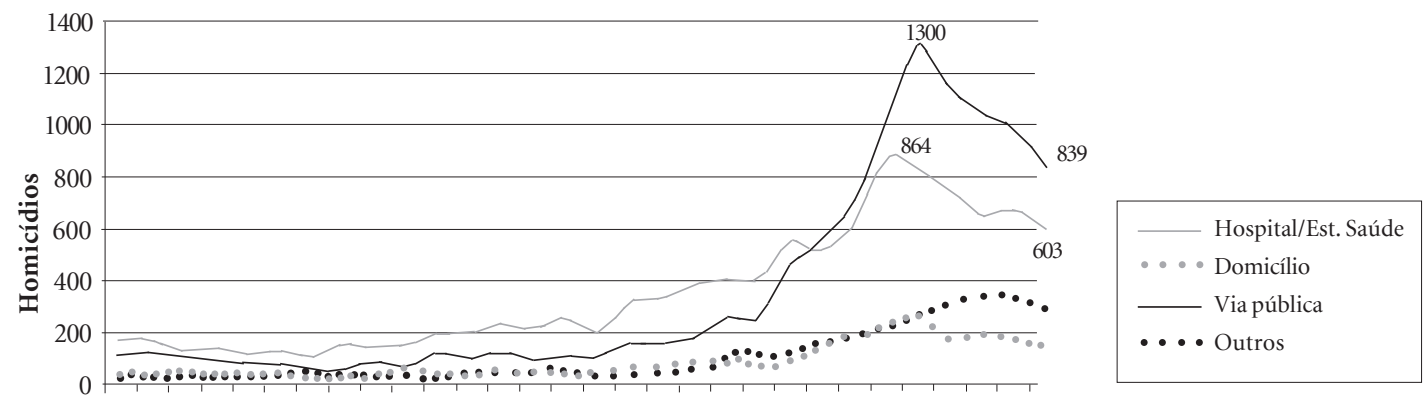

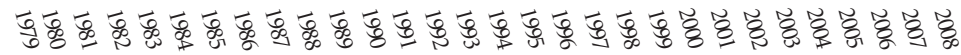

Gráfico 4. Homicídios registrados na RMBH, por Local de Ocorrência - 1979/2008.

Fonte: SIM/DATASUS (Elaboração Própria)

Outra questão a ser observada é a natureza territorial e localizada dos conflitos travados por estes grupos. Uma análise de 73 ocorrências de homicídio registradas entre 2007 e 2009 em 16 favelas da RMBH demonstra que $83 \%$ das vítimas foram assassinadas a, no máximo, 800 metros de suas residências. Essa característica territorializada dos assassinatos indica que boa parte dos conflitos cujo resultado foi a morte teve sua origem dentro das próprias comunidades, envolvendo atores locais que, não raramente, pos- suíam envolvimento com grupos armados e atividades criminosas como, por exemplo, o tráfico de drogas.

Entretanto, para os fins do presente trabalho, não se trata apenas de tentar compreender os impactos que o aumento numérico das mortes violentas projetou sobre a rotina policial e, principalmente, a atividade investigativa. Mais do que isso, trata-se de perceber os "desencaixes" cada vez maiores entre aquilo que, de um lado, é a crescente complexidade de um fenômeno criminal e o 


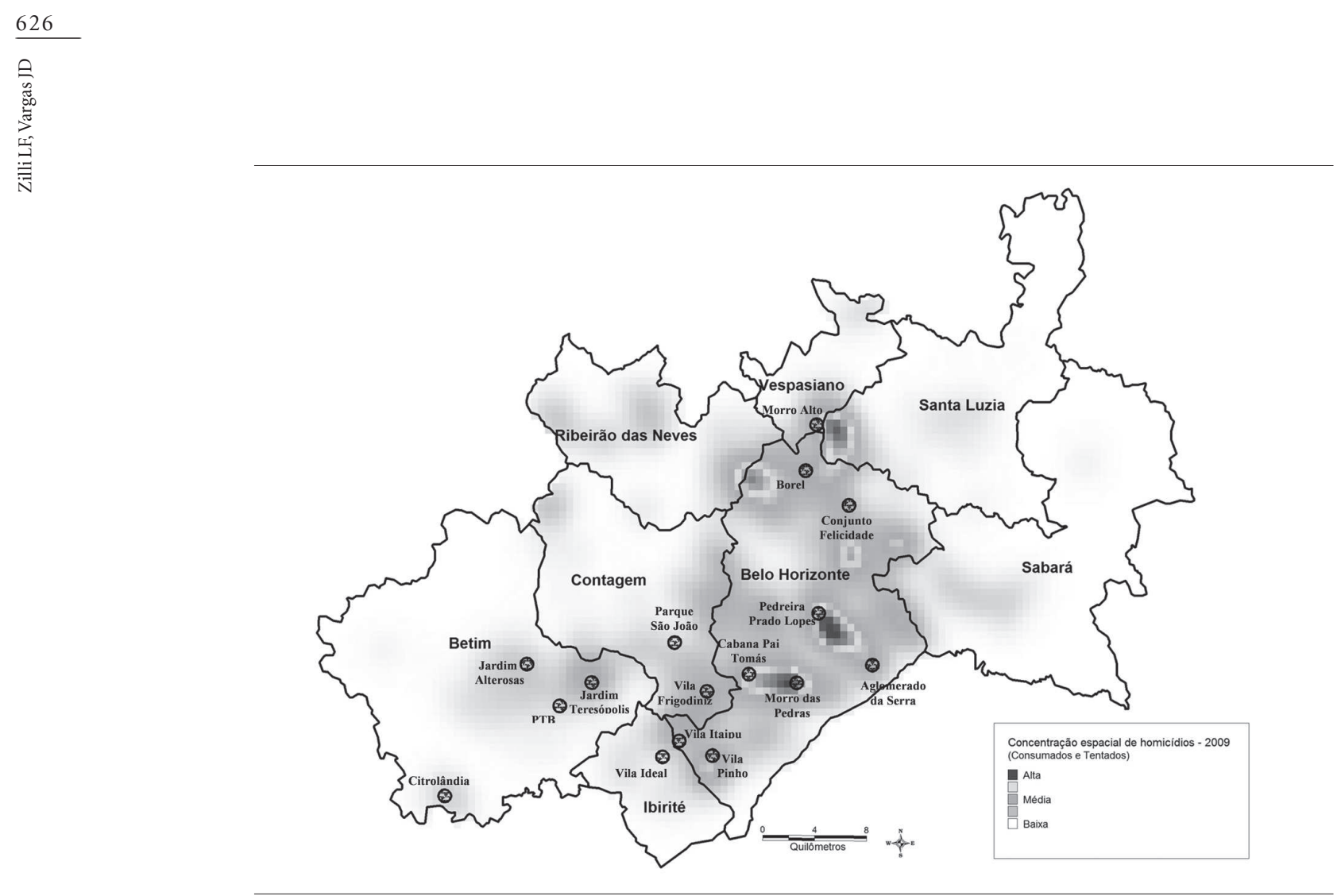

Figura 1. Concentração dos Crimes de Homicídio na RMBH - 2009

vasto leque de dinâmicas sociais envolvidas em sua conformação e, do outro lado, as práticas, os procedimentos, os dispositivos legais e as rotinas tradicionalmente prescritas à Polícia Civil para sua investigação e processamento.

\section{A investigação prescrita para os homicídios}

Segundo Mingardi ${ }^{16}$, qualquer investigação de homicídio pode ser dividida em duas etapas distintas, porém complementares: (1) investigação preliminar e (2) investigação de seguimento. Como investigação preliminar, entendem-se todos os procedimentos realizados especificamente na cena do crime, nos momentos imediatamente seguintes à chegada da polícia ao local do fato. A investigação de seguimento, por sua vez, refere-se aos procedimentos adotados posteriormente, já dentro do inquérito policial.

A investigação preliminar de homicídios pode ser caracterizada por basicamente cinco procedimentos: (1) a chegada de equipes policiais ao local do fato; (2) o isolamento e preservação da cena do crime; (3) a realização de "diligências" nos arredores do local do delito para tentativa de prisão do(s) criminoso(s); (4) o arrolamento de testemunhas presenciais e circunstanciais do fato;
(5) acompanhamento de todas as perícias realizadas no local do crime e no corpo da vítima.

Se estes procedimentos não levarem à identificação ou à prisão do $(\mathrm{s})$ criminoso $(\mathrm{s}) \operatorname{logo}$ após o crime, toma lugar a "investigação de seguimento", ou seja, as ações investigativas prescritas pelo instrumento do inquérito policial propriamente dito. A partir do levantamento da vida pregressa e dos depoimentos coletados, o investigador provavelmente já consegue formular algumas hipóteses sobre a identidade do(s) autor(es) e a motivação do crime. Essas hipóteses constituem linhas de investigação e levam os policiais a uma gama finita de suspeitos.

O que se espera da apuração é que ela consiga formular, de maneira clara, coerente e bem delineada, uma cadeia de evidências. Há de se observar se todas as provas foram obtidas de maneira lícita e se o conjunto probatório encontra-se ordenado de maneira coerente. A investigação do crime de homicídio possui, portanto, uma série de especificidades que não se encontram presentes em outros tipos de delitos. Para esclarecer a dinâmica de um homicídio, a investigação precisa se imiscuir na intrincada rede de relações e sentimentos que se forma entre os indivíduos. E isso faz com que a cadeia de evidências necessá- 
rias ao pleno esclarecimento de um assassinato seja, muitas vezes, muito mais complexa do que aquela que precisa ser estabelecida para a elucidação dos demais tipos de crime.

Apesar de todas as suas especificidades, a investigação dos homicídios não tem à sua disposição um leque de procedimentos diferente daquele disponível para a apuração de outros crimes. No modelo de apuração imposto pelo instrumento do inquérito policial (regulamentado pelo Código de Processo Penal de 1941), os procedimentos a serem utilizados para a investigação são basicamente os mesmos para todos os delitos. Por isso existe, entre os policiais, o consenso de que o homicídio exige do operador do inquérito uma grande capacidade de exploração do ferramental disponível.

Feitas essas considerações sobre as dinâmicas e os procedimentos inerentes à investigação dos homicídios, passamos a tratar da estrutura policial responsável pela apuração deste tipo de crime em Belo Horizonte. Como foi dito anteriormente, a ideia é observar como essa estrutura organizacional específica impacta a condução das investigações e, concomitantemente, as práticas cotidianas dos policiais.

\section{A investigação de homicídios em $\mathrm{BH}$ : contexto institucional}

Desde 2003, a estrutura da Segurança Pública em Minas Gerais vem passando por uma série de reformulações ${ }^{11}$. Naquele ano, o Governo do Estado extinguiu as secretarias de estado de "Segurança Pública" e de "Justiça”, unificando-as na Secretaria de Estado de "Defesa Social" (SEDS). Assim como outras áreas da administração pública estadual, esta secretaria tem suas ações monitoradas e avaliadas por meio de um modelo gerencial denominado "Estado para Resultados".

Submetidas a este modelo, todas as instituições ligadas à SEDS pactuam com o Governo do Estado um plano de atividades e metas conhecido como "acordo de resultados", cujos processos de avaliação são impulsionados por gratificações pecuniárias aos servidores envolvidos. Tais acordos preveem desde metas mais amplas de redução de índices de criminalidade, até objetivos mais restritos, referentes à realização de procedimentos administrativos específicos. No caso específico da Polícia Civil, o "acordo de resultados” prescreve o aumento do número de inquéritos relatados/concluídos, como ação indireta para a redução das taxas de homicídios.

\section{A Polícia Civil e a investigação dos homicídios em Belo Horizonte}

A Polícia Civil de Minas Gerais conta hoje com aproximadamente 10 mil agentes, distribuídos em 2.543 unidades (das quais apenas 819 são efetivamente operacionais). Para os fins da presente pesquisa, elegeu-se a Divisão de Crimes contra a Vida (DCcV), centro que congrega seis Delegacias Especializadas de Homicídios (DEH) responsáveis pelo registro e investigação de todos os assassinatos cometidos em Belo Horizonte. Além das delegacias, a divisão também coordena o serviço de remoção de cadáveres (rabecão) e postos de plantão instalados em três grandes hospitais públicos de Belo Horizonte. Ao todo, 194 policiais compõem a equipe da DCcV. São 14 delegados, 25 escrivães e 155 agentes de polícia.

\section{Responsabilidade Territorial}

Até 2004, a DCcV contava com apenas cinco delegacias (com apenas um delegado em cada unidade), sem que nenhuma delas fosse atrelada a qualquer jurisdição territorial. A responsabilidade sobre as investigações era dividida de acordo com o dia da semana em que os crimes eram cometidos, independentemente da região da cidade.

Era como funcionava o antigo sistema de permanência. Cada dia da semana, um delegado e sua equipe ficavam escalados para ficar de permanência. Todos os crimes que aconteciam naquele dia eram de responsabilidade dessa equipe. Cabia a ela ir ao local de crime, fazer as investigações preliminares de local e depois instaurar o inquérito para fazer as investigações de seguimento. (Delegado de Homicídios)

Segundo os delegados e agentes entrevistados pela pesquisa, esse sistema atendia satisfatoriamente as escalas funcionais, mas se mostrava extremamente contraproducente para a investigação dos homicídios, uma vez que os policiais não tinham condições de se dedicar à compreensão mais aprofundada das dinâmicas criminais vigentes nas localidades onde os crimes aconteciam.

Ao final de 2004, este sistema foi modificado e adequado à lógica da especialização e da responsabilização territorial. A DCcV ganhou mais uma delegacia e cada uma de suas seis unidades passou a ter como jurisdição uma determinada área da cidade. Em termos práticos, esta nova alocação tinha basicamente dois objetivos: permitir à SEDS aumentar os níveis de "accountability" do trabalho realizado pelas delegacias de 
homicídio (uma vez que cada unidade era responsável por uma região da cidade) e, pelo menos teoricamente, possibilitar aos investigadores conhecer de maneira mais aprofundada as dinâmicas criminais locais e, consequentemente, facilitar a investigação dos homicídios.

\section{Expediente e Plantão}

Esse sistema de regionalização do trabalho das Delegacias Especializadas de Homicídios, no entanto, acabou impactando somente as investigações de seguimento. Para as investigações preliminares, a DCcV manteve o sistema de permanência (plantão), enviando equipes aleatoriamente definidas para os locais de crimes, em função do dia da semana em que os homicídios ocorriam. Na prática, tal ordenamento desonerou a escala de trabalho dos agentes do expediente (deixando mais um dia da semana livre para trabalhos de investigação regionalizados), mas continuou submetendo a investigação dos homicídios à lógica fracionada das escalas de serviço.

\section{Impactos do sistema de permanência sobre a investigação}

Neste ponto, torna-se possível identificar em que medida a estrutura organizacional impacta o andamento do trabalho policial e a prática da investigação. O sistema de permanência adotado pela DCcV para as investigações preliminares, por exemplo, acabou se tornando uma contradição dentro da orientação geral de regionalização e especialização das investigações de homicídio. Ao manter as investigações preliminares sob a responsabilidade de equipes sem conhecimento específico sobre as dinâmicas criminais locais, ou mesmo qualquer relação com os agentes responsáveis pela investigação de seguimento, a chefia da DCcV acabou criando um "hiato" entre as duas fases da apuração dos crimes.

Quebrou-se a lógica da especialização e da regionalização dos trabalhos investigativos, tão necessária à adequada apuração dos homicídios, para beneficiar o ordenamento funcional burocrático das escalas de trabalho. Do modo como o trabalho foi organizado na $\mathrm{DCcV}$, os agentes de plantão podiam até se tornarem especialistas em coleta de provas em locais de crimes, mas, definitivamente, não compreendiam a fundo a dinâmica de criminalidade das localidades onde atuavam. Isso prejudicava sensivelmente o conjunto do trabalho investigativo e criava descontinuidade entre as duas fases da investigação dos homicídios.
Esse descompasso pôde ser observado em um local de homicídio acompanhado por um dos pesquisadores no início de 2009, quando uma equipe de plantonistas da $\mathrm{DCcV}$ foi acionada para ir até um hospital público de $\mathrm{BH}$ para checar a informação de que duas vítimas de tentativas de homicídio teriam dado entrada na unidade e que uma delas havia falecido há poucos instantes. Após tomar o depoimento de familiares do jovem morto, os agentes foram até a enfermaria da unidade para entrevistar o sobrevivente. Algumas perguntas genéricas foram feitas à vítima, que não forneceu mais detalhes sobre o crime.

Posteriormente, em contato com policiais militares que trabalham exclusivamente na região onde o crime havia ocorrido, os agentes foram informados que, na verdade, o sobrevivente era um traficante atuante na região norte da cidade e que ele teria sido o alvo principal do atentado e não o rapaz morto. Segundo os agentes, os policiais militares só detinham essa informação porque trabalhavam exclusivamente na região do crime e, diferentemente deles, conheciam profundamente toda a complexidade da dinâmica criminal local, associada a intrincados processos de rivalidades entre gangues e disputas relacionadas ao tráfico de drogas.

O fato de todos os levantamentos de local serem feitos por policiais do plantão atrapalha demais as investigações iniciais. Veja o nosso caso. A gente foi pra fazer levantamento em uma área que não conhecíamos. Entrevistamos um rapaz achando que ele era uma simples vítima casual, quando na verdade era um criminoso procurado e o principal alvo da ação. Se fôssemos especializados naquela área, não teríamos 'comido essa mosca'. Saberíamos quem era aquele rapaz. Acabamos fazendo um trabalho muito aquém do que poderia ter sido feito, o que vai prejudicar quem for assumir a investigação depois. (Agente de Polícia)

\section{Volume de inquéritos}

$\mathrm{Na}$ época em que esta pesquisa foi realizada, registros do cartório central da $\mathrm{DCcV}$ indicavam que cada um dos 13 delegados operacionais da unidade (um respondia pela chefia da Divisão) tinha sob sua responsabilidade cerca de 500 inquéritos. Isso significa dizer que aproximadamente 6.500 inquéritos encontravam-se em tramitação na unidade quando este estudo estava sendo concluído. Ainda segundo a contabilidade do cartório central, entre os anos de 2006 e 2008, as unidades da DCcV instauraram, em média, 2,6 inquéritos de homicídios por dia. Em contrapartida, a 
média diária de inquéritos relatados neste período não ultrapassou 1,6. Mantida essa proporção, tal situação configuraria um aumento de exatamente 365 inquéritos por ano em tramitação na unidade, somados ao volume já existente.

Para tentar reverter essa situação, a Secretaria de Defesa Social instaurou, em outubro de 2008, um sistema de metas que afetou sensivelmente a rotina das delegacias da $\mathrm{DCcV}$ : determinou-se que, a partir daquela data, cada delegado passava a ser obrigado a relatar, no mínimo, dez inquéritos por mês. A meta valeu entre outubro e dezembro de 2008, sendo elevada para 12 relatórios por mês a partir de janeiro de 2009. A meta, no entanto, não estipulava qualquer proporção entre as modalidades de relatoria, o que deixava os delegados absolutamente livres para relatar os inquéritos por indiciamento (quando a polícia acredita ter solucionado o caso e encontrado o culpado), ou por arquivamento (quando a polícia se declara oficialmente incapaz de solucionar o crime).

Além disso, o programa de metas continha em si um sistema de acúmulo de dívidas. Ou seja, caso o delegado não relatasse a cota mensal de inquéritos estipulada, abriria o mês seguinte devendo o que ficou faltando. No entanto, a recíproca não lhes era oferecida: caso um delegado relatasse acima da média estipulada, essa "sobra" não abateria a meta do mês seguinte. Obviamente, isso fez com que os delegados optassem por não relatar mais do que a cota mensal estipulada. Ao contrário, a pesquisa pôde constatar que, após cumprirem sua cota, alguns delegados "guardavam” inquéritos relatados para serem usados nos meses seguintes. Nas palavras de um delegado.

Durante o mês de dezembro, as delegacias estavam com praticamente todos os seus agentes em um curso na Academia de Polícia. Não tivemos como investigar nada naquele mês. Por isso eu usei uma 'gordura' que eu tinha acumulada e cumpri minha meta de dezembro. Esse mês eu ainda tenho alguns relatórios para desovar, mas em fevereiro eu não sei como vou fazer porque já vou ter queimado toda minha gordura. (Delegado de Homicídios)

\section{Impactos do sistema de metas sobre a investigação}

Quais impactos o sistema de metas, implantado pela SEDS em outubro de 2008, projetou sobre o trabalho policial e a prática da investigação dos homicídios? Pressionados pelo sistema de avaliação de desempenho, os delegados de homicídios admitiam abertamente o uso de al- gumas estratégias para o cumprimento das metas estabelecidas. O mais corriqueiro foi ironicamente definido por eles como "estratégia revisionista”. Tal expediente consistia, basicamente, em recorrer ao estoque de inquéritos antigos da delegacia e, usando como justificativa o longo período decorrido e as poucas diligências realizadas por equipes anteriores, relatá-lo pedindo arquivamento. Durante o período em que este estudo esteve em campo, constatou-se que alguns delegados pediram o arquivamento de inquéritos sem ouvir uma única testemunha sequer (nem mesmo parentes de primeiro grau da vítima).

Ainda durante a pesquisa, delegados, agentes e escrivães foram unânimes em concordar que a adoção de um sistema de metas, com a imposição de uma cota mensal de inquéritos relatados, pode gerar efeitos perversos sobre a condução e a efetividade das investigações, principalmente se não houver qualquer controle sobre a qualidade desses procedimentos, ou mesmo qualquer correlação entre a produção desses relatórios e o trabalho posterior do Ministério Público.

Com esse sistema de metas, as investigações perderam muito em qualidade. Antes tínhamos mais cuidado na coleta de provas, tomávamos mais depoimentos, podíamos esperar a chegada dos laudos, desenvolvíamos as linhas de investigação. Agora, tem inquérito que a gente força a barra pra relatar e fica torcendo para o MP aceitar. Tem inquérito que é feito nas coxas mesmo. Meu critério hoje é relatar o que está mais fácil. Crime passional, por exemplo, já vem apurado. Todos os que chegam eu relato. Se antes o foco eram os crimes de tráfico de drogas, hoje é relatar o que está mais fácil. (Delegado de Homicídios)

\section{A complexificação das dinâmicas criminais e a apuração dos crimes}

Além das questões de ordem institucional, cabe observar os impactos que o recrudescimento e a complexificação do problema dos homicídios projetou sobre as práticas investigativas. Por parte dos investigadores, a queixa mais recorrente é a de que o atual volume de casos (somado à pressão pública e institucional pela maior celeridade no processamento dos crimes) solapou a qualidade da investigação policial, submetendoa ao ritmo cartorário e ritualístico do inquérito policial. Os policiais parecem entender que o próprio instrumento do inquérito tornou-se uma ferramenta pouco ágil para a apuração de crimes, sobretudo se forem considerados o aumento exponencial do número de casos e a complexifi- 
cação das dinâmicas que envolvem os crimes de homicídio.

Se a gente não tiver o inquérito, não temos serviço. Todo nosso serviço é baseado no inquérito e só aparece através dele. Mas o inquérito como peça hoje, para a nossa realidade, ele é extremamente demorado. Qualquer coisa que você precisa demora muito tempo. Os trâmites legais são muito complicados. (Agente de Polícia)

Especialmente quando se trata da apuração de crimes cometidos por grupos armados em favelas, uma das questões mais discutidas pelos investigadores é a falta de instrumentos legais que possibilitem a realização de investigações em sigilo. Os agentes reconhecem que, de certo modo, o caráter aberto do inquérito policial garante a transparência necessária aos procedimentos policiais, garantindo os direitos dos investigados. No entanto, os policiais argumentam que é justamente o caráter "aberto" do instrumento que prejudica a apuração de crimes, uma vez que as testemunhas se veem intimidadas em depor contra os investigados.

Tal cenário se configura ainda mais grave nos dias de hoje, em função de duas questões: a primeira refere-se ao fato de grande parte dos crimes ser cometida por grupos criminosos armados, com alto poder de intimidação local; a segunda é devida ao próprio caráter cartorial do inquérito, que se sobrepõe ao dinamismo e à tecnicidade das investigações, relegando à prova testemunhal importância muito superior às chamadas provas técnicas.

Desde que entrei na Homicídios percebi esse problema nos inquéritos. É só testemunhal, muito fraco. A testemunha pode mudar de ideia, pode ser convencida, pode ser comprada. Isso dificulta muito o nosso trabalho. (Agente de Polícia)

Tem casos em que a gente tem inquérito e testemunhas. Aí chega o advogado, faz copia do inquérito e apresenta as testemunhas pro autor que nós estamos apurando. Daqui a pouco, eles mesmos trazem as testemunhas de volta à delegacia e elas negam tudo. Pedem para retirar o depoimento porque foram ameaçadas e estão com medo. (...) Isso aí é comum acontecer. Os caras arrumam celular dentro da cadeia e ameaçam testemunha. (Agente de Polícia)

A sociedade não pode ser dependente da confissão pra ver homicida punido. Existem técnicas investigativas pra lidar com ausência de confissão e falta de testemunha presencial. Mas a gente virou refém das provas fáceis que é a confissão e testemunha presencial, por déficit investigativo nosso. (Delegado de Homicídios)
O que se percebe é que, a despeito de haver uma percepção clara sobre a crescente complexidade assumida pelos fenômenos criminais e a consequente necessidade de adotar procedimentos mais céleres, eficazes e técnico-científicos, ainda existe pouco consenso entre os policiais sobre a melhor forma de se fazê-lo.

\section{Considerações finais}

Nesse artigo, buscamos contextualizar, em relação ao quadro nacional brasileiro, os altos índices de violência e mortes entre jovens moradores de vilas e favelas em Belo Horizonte, observados nos últimos anos, bem como o impacto desses índices sobre a atividade investigativa da polícia local. Procuramos discutir o quanto a investigação policial em Belo Horizonte encontra-se preparada ou não para fazer frente ao novo padrão de criminalidade e ressaltamos as mudanças institucionais empreendidas, a partir de 2003, para lidar com o vertiginoso crescimento dos homicídios experimentado pela capital mineira a partir de meados dos anos 1990.

Por um lado, identificamos que o novo padrão de violência letal em Belo Horizonte caracteriza-se pela conformação de pequenos grupos de jovens armados ou gangues, atrelados aos microterritórios de vilas e favelas, com posse de armas de fogo e em constantes conflitos entre si. Estes conflitos parecem se dar não apenas a partir de um vasto leque de disputas comunitárias e interpessoais, mas cada vez mais em função de processos de estruturação de atividades criminosas (notadamente o tráfico de drogas) gerando uma grande quantidade de mortes e agregando maiores níveis de complexidade ao fenômeno criminal.

$\mathrm{Na}$ tentativa de conter o crescimento das taxas de homicídios e se adequar melhor à crescente complexificação do fenômeno, a atividade policial investigativa vem sendo reestruturada em Belo Horizonte. No entanto, é possível identificar alguns "desencaixes” que, nas palavras dos próprios investigadores, ainda comprometem sensivelmente sua eficiência e eficácia.

O primeiro desses desajustes pode ser visto na fase preliminar de investigação dos homicídios: a despeito de grande parte dos assassinatos estarem claramente relacionados a conflitos de âmbito estritamente territorial, os levantamentos preliminares não seguem esta mesma lógica. Todas as investigações preliminares são feitas por equipes de policiais plantonistas, sem qualquer 
conhecimento mais específico ou aprofundado das dinâmicas criminais e conflitivas vigentes nas áreas em que os crimes ocorrem.

Como as investigações de seguimento são feitas por equipes territorialmente dedicadas e especializadas, observa-se um claro "hiato" entre as duas fases de investigação, aspecto que prejudica sensivelmente sua efetividade. Os próprios investigadores argumentam que há a necessidade de integrar as duas fases da investigação, fazendo com que todo processo seja conduzido por equipes territorialmente especializadas e dedicadas. Além de a conformação territorial em todo o processo de investigação se adequar melhor à lógica de grande parte dos homicídios, a articulação entre as fases preliminar e de seguimento certamente mostrar-se-ia capaz de ultrapassar os procedimentos arcaicos e formalistas do inquérito policial sem, contudo, incorrer em violações de direitos e garantias.

Quanto ao sistema de metas e avaliações imposto sobre os policiais, parece haver um reconhecimento unânime sobre a importância de se mensurar a eficiência e a eficácia do trabalho investigativo. Entretanto, parece ser mais produtivo (e menos sujeito a deturpações) visar a qualidade do trabalho de investigação realizado e não a produção meramente quantitativa, como vem ocorrendo. A simples imposição de metas quantitativas de inquéritos relatados não vem contribuindo positivamente para a elucidação dos homicídios, sobretudo aqueles envolvendo grupos de jovens armados, moradores de vilas e favelas.
Por fim, resta destacar o "desencaixe" cada vez mais agudo entre a crescente complexificação das dinâmicas sociais e criminais responsáveis pela produção de altíssimos níveis de violência letal e o caráter inquisitorial, formalista e cartorial do inquérito policial. De modo geral, as práticas e os instrumentos adotados para a apuração dos homicídios continuam atrelados, quase que exclusivamente, à tomada de depoimentos de testemunhas e à obtenção de confissões dos autores, lógica instrumental tradicionalmente utilizada para a apuração dos assassinatos motivados por questões interpessoais e comunitárias ${ }^{17}$.

Em contrapartida, existem fortes indícios de que os homicídios registrados em favelas de $\mathrm{BH}$ têm, crescentemente, se relacionado com a atuação de grupos armados e seus intrincados processos de estruturação de atividades criminosas. Nesse contexto, as mortes passam a decorrer não apenas de conflitos interpessoais, mas, sobretudo, de uma infinidade de questões inerentes ao cotidiano dos grupos e aos empreendimentos criminosos controlados por eles. Por envolver elementos de ordem tão diversa e com crescente grau de complexidade, torna-se claro que esse novo perfil de violência demanda práticas investigativas cada vez mais sofisticadas e menos atreladas a modelos tradicionais de investigação cartorial. Nesse sentido, faz-se necessária a modernização efetiva da polícia, dentre outros com maiores investimentos em metodologias técnico-científicas de investigação, em detrimento dos modos tradicionais prescritos pelo inquérito policial.

\section{Colaboradores}

LF Zilli e JD Vargas participaram igualmente de todas as etapas de elaboração do artigo. 


\section{Referências}

1. Gawryszewski VP, Costa LS. Social Inequality and Homicide Rates in São Paulo City, Brazil. Rev Saude publica 2005; 39(2):191-197.

2. Beato Filho CC, Assunção RM, Silva BFA, Marinho FC, Reis Ilka A, Almeida MCM. Conglomerados de Homicídios e o Tráfico de Drogas em Belo Horizonte, Minas Gerais, Brasil, de 1995 a 1999. Cad Saude publica 2001; 17(5):163-171.

3. Paim JS, Nascimento CM, Mascarenhas JCS, Silva LMV. Distribuição Espacial da Violência: mortalidade por causas externas em Salvador. Rev Panamericana de Saúde Pública 1999; 6(5):321-332.

4. Rivero PS. Segregação urbana e distribuição da violência: homicídios georreferenciados no município do Rio de Janeiro. Dilemas - Revista de Estudos de Conflito e Controle Social. 2010; 3(9):117-142.

5. Goertzel Ted, Kahn T. The Great São Paulo Homicide Drop. Homicide Studies 2009; 13(4):398-410.

6. Musumeci L, Silva GF, Conceição GMS. Geografia da Violência na Região Metropolitana do Rio de Janeiro - 2000 a 2005. Boletim Segurança e Cidadania 2006; 05(11).

7. Beato Filho CC. Crime e Cidades [tese]. Belo Horizonte: Universidade Federal de Minas Gerais (UFMG); 2010.

8. Zaluar A. Integração Perversa: pobreza e tráfico de drogas. Editora FGV: Rio de Janeiro; 2004.

9. Misse M, Nascimento A, Renoldi B, Grillo CC, Neri NE. O Inquérito Policial no Rio de Janeiro: mudanças recentes, alcances, tradições e especificidades. In: Misse M, organizador. O Inquérito Policial no Brasil: uma pesquisa empírica. Rio de Janeiro: Booklink; 2010. p. 23-101.

10. Misse M, Vargas JD. A produção decisória do sistema de justiça criminal no Rio de Janeiro ontem e hoje: um estudo preliminar. Rev Brasileira de Ciências Criminais 2009; 17(77):237-260.
11. Sapori LF. Segurança Pública no Brasil: desafios e perspectivas. Rio de Janeiro: Editora da FGV; 2007.

12. Ratton JL. Violência Endêmica-Homicídios na cidade do Recife: dinâmica e fluxo no Sistema de Justiça Criminal. Rev Ministério Público de Pernambuco 2006; 1(1):21-139.

13. Lima RK. Cultura Jurídica e Práticas Policiais: a tradição inquisitorial. Rev Brasileira de Ciências Sociais 1989; 4(10):65-84.

14. Vargas JD, Zilli LF. Uma abordagem empírica do Inquérito Policial: o caso de Belo Horizonte. In: Miss M, organizador. O Inquérito Policial no Brasil: uma pesquisa empírica. Rio de Janeiro: Booklink; 2010. p. 102-190.

15. Minas Gerais. Secretaria de Estado de Defesa Social (SEDS). Relatório Técnico do Grupo de Monitoramento de Gangues (GMG). Minas Gerais: Governo do Estado de Minas Gerais; 2009.

16. Mingardi G. A Investigação de Homicídios: a construção de um modelo. Brasília: Ministério da Justiça; 2005.

17. Paixão AL, Martins HT, Sapori LF. Métodos e acidentes de trabalho: violência, legalidade e polícia. Análise \& Conjuntura 1992; 7(2 e 3):76-91.

Artigo apresentado em 18/04/2012

Aprovado em 10/05/2012

Versão final apresentada em 15/05/2012 